\title{
Perception of Anemic Women Instead of Herbal Medicine and Dietetics in Treatment of Nutritional Anemia
}

\author{
F. Ben Slama1,2, S. Médini³, N. Ben Mansour ${ }^{1,2}$, R. Chamli³ ${ }^{3}$ H. Aounallah-Skhiri'1,2, \\ M. Hsairi ${ }^{1,2}$, O. Belhadj ${ }^{4}$ \\ ${ }^{1}$ National Institute of Public Health, Tunis, Tunisia \\ ${ }^{2}$ Laboratory of Monitoring and Nutritional Epidemiology in Tunisia, National Institute of Nutrition, Tunis, Tunisia \\ ${ }^{3}$ Department of Herbal Medicine, Faculty of Pharmacy of Monastir, Monastir, Tunisia \\ ${ }^{4}$ Laboratory of Biochemistry and Biotechnology, Faculty of Sciences of Tunis, Tunis, Tunisia \\ Email: benslamafethi@yahoo.fr
}

Received 4 March 2014; revised 4 April 2014; accepted 11 April 2014

Copyright (C) 2014 by authors and Scientific Research Publishing Inc.

This work is licensed under the Creative Commons Attribution International License (CC BY).

http://creativecommons.org/licenses/by/4.0/

(c) (i)

Open Access

\section{Abstract}

The iron deficiency anemia is relatively common among young women in Tunisia. Phytotherapy has a place in the treatment of this deficiency anemia. Objective: The objective of this work is to describe the perception of anemic women vis-à-vis the use of herbs and dietary and adapted through a survey in Greater Tunis. Method: A questionnaire survey was conducted among 124 anemic women, recruited from public health facilities in Greater Tunis. Results: The majority of women surveyed $(84.7 \%)$ had secondary or university education, $10.5 \%$ primary and $4.8 \%$ were illiterate. Among the women surveyed, $93.5 \%$ received a replacement iron-based medical treatment. Among the iron-rich foods, they are legumes that were most appreciated by almost all respondents. While food sources of vitamin B12 and folate were ignored by the majority of women $(68 \%)$. Two out of three women were unaware of the importance of meat products as the main source of iron, vitamin B12 and folate. Almost half of the women had the habit of consuming tea every day just after meals and they convict that increases the amount of blood. The frequency of the use of traditional medicinal plants by women surveyed in order to treat their anemia was $40 \%$. These women were often advised to use plants by other anemic women and traditional herbalists whose skills in this area were acquired by experience and transmitted from father to son without adequate scientific training. The plants most frequently used were fenugreek, cumin, oregano, rosemary and parsley. Conclusion: These data clearly found the need to intervene for better education of women and girls by the establishment of a nutrition education program associated with other environmental actions. If herbal keeps a place in iron deficiency anemia, the practice of 
herbal medicine and the preparation of its remedies require the acquisition of institutional competence within the public health authorities whose training must be constantly updated.

\title{
Keywords
}

\author{
Women, Iron Deficiency, Anemia, Herbal Therapy, Diets
}

\section{Introduction}

Nutritional anemia is a major public health problem. According to the World Health Organization (WHO), there are in the world 1.6 billion anemic people. The most affected age groups are children aged $0-4$ and women of childbearing age [1]-[4]. The investigation by the National Institute of Nutrition and Food Technology in 2002 on nutritional anemia in Tunisia showed that they affect more women of childbearing age in Greater Tunis (28.9\%) than in the South West (30.7\%). This is essentially moderate anemia (hemoglobin between 10.9 and 7 $\mathrm{g} / \mathrm{dl}$ ). The severe form (hemoglobin $<7 \mathrm{~g} / \mathrm{dl}$ ) affects only $1.2 \%$ in Greater Tunis and $0.7 \%$ in the South West [5]. To reduce the effects of this anomaly, some anemic women use herbal medicine and follow a suitable diet. Increased use of plants and natural products has been reported [6] [7] and is linked to increased incidence of some chronic diseases, increased frequency of adverse drug synthesis and cost very high for some pharmaceutical products [8]. Today, herbal medicine is based on both tradition and scientific research according to official standards of modern medicine. In parallel with the use of plants in the treatment of some diseases, diet plays an important role in the prevention and mitigation of some chronic diseases. It is in this context that we realized this work, which aims to describe the perception of anemic women against the use of herbs and dietary and adapted through a survey in Greater Tunis. The results of this work could be conductive lines for programming of health and nutrition education programs intension of young anemic women and herbalists.

\section{Materiels and Methods}

\subsection{Study Population}

The source of the study population were anemic women who have undergone during the period January-March 2012 to the outpatient hematology clinic of the hospital "Aziza Othmana” Centre Health Care Base of soukra or outpatient gynecology Hospital Abdrahmen Mami Ariana. In collaboration with the supervisor of each department and while trying not to disturb the work flow within the department, and from the medical records of consultation, we conducted a random draw from May to October from women a numbered list of anemic women consultants, every day of our visit list. We met the exacting standards of ethics in particular obtaining informed consent from respondents and confidentiality.

\subsection{Methods}

It is a questionnaire administered by an interviewer preformed. The data were related to the identification of women, women's knowledge against the benefits of food sources of iron, folate and vitamin B12, their place in the spontaneous feeding them. We have studied the usual frequency of consumption of food sources of iron, B12 and folate saw the group of women surveyed and presenting a list of 12 foods rich in these micronutrients known component and our Tunisian dishes. To simplify the presentation of our results, we adopted arbitrary classification frequencies and considering that the food is often consumed if consumed more than 3 times a week, once a day or several times a day. If the food is consumed less than twice per week assuming rarely consumed. The last part of our questionnaire is interested in the perception of the role of herbal remedies and recipes used in the treatment of anemia in women.

\subsection{Statistical Analysis}

Data were entered using Excel 2007 software. Statistical analysis was performed using SPSS Version 11.5 software. 


\section{Results}

A total of 124 women were recruited. The average age was $30.5 \pm 7.2$ years. The majority of women surveyed (84.7\%) had secondary or university education, $10.5 \%$ primary and $4.8 \%$ were illiterate. Over a third (37\%) women were not engaged in gainful employment. The mean duration of anemia was $8.5 \pm 5.0$ years and the majority of women were anemic for more than 10 years. About 2 out of 3 women among the respondents (65.3\%) were aware of the main symptoms of anemia namely asthenia, headache, dizziness, pallor and hair loss.

Regarding the treatment of anemia, 93.5\% had a replacement iron-based medical treatment, but women reported a lack of adherence to prescribed treatments. The analysis of nutritional knowledge of women showed that the majority of them (61\%) knew the daily iron needs of premenopausal women and only $2 \%$ of them were completely unaware of the food sources iron. Figure 1 shows food sources of iron reported by our surveyed.

Legumes were well appreciated by almost all respondents as a source of iron. The lenses were the most frequently cited (81\%), followed by chickpeas. A minority of women reported fenugreek, beans and white beans. Green vegetables, especially spinach were cited by about three-quarters of women as being rich in vitamins and beneficial health giving foods. However, foods of animal origin (liver, red meat and fish) were relatively unknown by women and only 39.5\% of anemic women cited the liver as a source of iron. Cereals (sorghum, corn, barley, pasta) were seen by some women as a preventive against food anemia. The fruits were seldom mentioned, with the exception of apples that were considered by more than half of women as feature haematinics properties. Chocolate and dried fruit were also rarely mentioned.

The majority of women (68\%) were unaware of the dietary sources of vitamin B12 and folate. On the other hand, two out of three women were unaware of the importance of meat products as the main source of iron, vitamin B12 and folate.

Table 1 summarizes the frequency of use of the usual sources of food iron, vitamin B12 and folate.

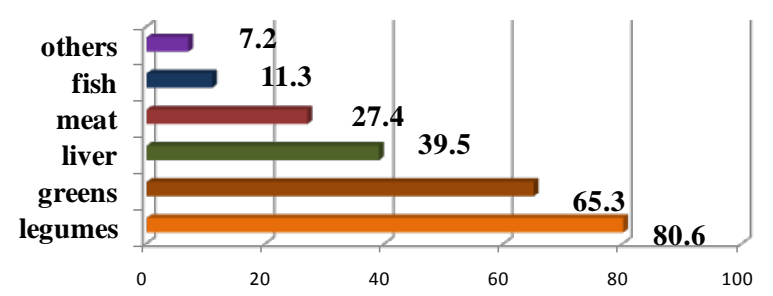

(\%)

Figure 1. Food sources of iron reported by respondents.

Table 1. Frequency of consumption of food sources of iron, folate and B12.

\begin{tabular}{cccc}
\hline \multirow{2}{*}{ Foodstuffs } & & Frequency of consumption (\%) & \\
\cline { 2 - 4 } & Never used & Rarely consumed & Frequently consumed \\
\hline Liver & 29.0 & 66.1 & 4.8 \\
Fatty fish & 20.2 & 69.4 & 10.5 \\
Egg & 12.1 & 43.5 & 44.4 \\
Fenugreek & 71.8 & 23.4 & 4.8 \\
White beans & 13.7 & 83.9 & 2.4 \\
Lentils & 15.3 & 71.8 & 3.9 \\
Pois chiche & 16.9 & 46.8 & 36.3 \\
Pearsley & 5.6 & 50.0 & 44.4 \\
Spinach & 23.4 & 71.0 & 5.6 \\
Barley & 15.3 & 71.0 & 13.7 \\
Cocoa & 20.2 & 44.4 & 35.5 \\
Corn & 46.8 & 41.9 & 11.3 \\
\hline
\end{tabular}


It is clear from these results that legumes and cereals were the most commonly consumed.

Conviction that tea consumption increases the amount of blood, $45 \%$ of women surveyed had the habit of drinking tea every day just after meals.

The majority of women (76.6\%) thought that a dietary regimen is useful for preventing and treating anemia. However, one in five women (19.4\%) followed only regular dietary advice.

Table 2 summarizes the results for the perception of women anemic against the use of traditional medicinal plants to treat their anemia. Approximately $40 \%$ of women surveyed have used plants. Surveys have shown that more than half of the users of plants (54.8\%) were advised by other anemic while $40.5 \%$ by herbalists and $4.7 \%$ by a general practitioner doctor. The plants most frequently used were fenugreek, cumin, oregano, rosemary and parsley.

The infusion and decoction were the main modes of preparation used by anemic women. Non-users of the plants discussed many reasons, among other insurance offered by allopathy in comparison with herbal medicine, not knowledge of these plants and their potential effectiveness in the treatment of anemia, not belief efficiency of plants and the fear of side effects thereof. For women who have tried herbal and stopped the use of plants, we found that $55 \%$ did so after apparent recovery, $19 \%$ because of the bitter taste of some plants, $14 \%$ and mistrust $12 \%$ result in the occurrence of complication.

\section{Discussion}

The main objective of this work was to know the role of dietary and herbal medicine in the treatment of anemia in women perception. The majority of women surveyed had a moderate or insufficient diet on the anemia knowledge. The results of this study are comparable to those in the literature. According to a study conducted in Bangladesh on knowledge and dietary behavior of young anemic [9], 73.8\% of participants completely ignored the food sources of iron. Another study during 2011 [10] investigated the nutritional status of rural women in India and found a low level of knowledge against dietary anemia. Similarly the results of the study conducted in 2009 [11] among Iranian women showed a low level of knowledge on the role of vitamins B9 and B12 as a preventive factor for anemia. In addition, work carried out in 2004 among pregnant women in Mongolia [12] and the UK [13] showed an insufficient level of knowledge against dietary anemia. Furthermore, we found that $65.3 \%$ of women surveyed know the main symptoms of anemia namely asthenia, headache, dizziness, pallor and hair loss. These results are consistent with those of the two studies respectively in Palestine in 2007 [6] and in Tunisia in 2002 [5] from anemic women.

Lack of awareness by stakeholders (health personnel, curriculum, mass media) against the diet and symptoms of anemia is the main determinant of this lack of knowledge. Our survey showed that $18.5 \%$ of anemic women only frequently consumed food sources of iron, vitamin B12 and folate with a predominance of legumes and green vegetables. These foods have the disadvantage of containing only non-heme iron (weakly absorbed), and also be rich in compounds inhibiting the absorption of the iron (Phytates polyphenolic compounds). Against by,

\begin{tabular}{cc}
\hline Table 2. Plants used by women in the treatment of anemia. \\
\hline Cited plant & Frequency of use (\%) \\
\hline Fenugreek & 45.2 \\
Nigela & 31.0 \\
Oregano & 26.2 \\
Rosemary & 21.4 \\
Parsley & 14.3 \\
Ginger & 9.5 \\
Mint & 12.0 \\
Barley + chamomile + verbena & 7.4 \\
Arabsenna + Sorghum & 4.7 \\
Lin (flax) + Rihan & 2.4 \\
\hline
\end{tabular}


the foods of animal origin (meat, liver, fish...) which represent the sole source of heme iron (iron good quality characterized by a better digestive absorption and facilitating the absorption of non-haem iron) and main source of vitamin B12 and folate, were rarely consumed.

Similar to our results have been reported. The national study on anemia conducted in 2002 [5] has shown that the daily dietary intake of iron for women of childbearing age only covered $70 \%$ of the recommended daily intake, and almost all women appreciated the plant foods especially legumes and green leafy vegetables, causing low iron bioavailability reflecting the daily intake substandard, since it is made mainly in the non-heme form (87\% of total iron) then that the consumption of meat products (meat, poultry, fish, liver) was insufficient.

This feeding behavior is not specific to Tunisian women. Indeed, the results of a WHO study [12] in Mongolia showed that $17.8 \%$ of 689 pregnant women surveyed rarely consumed meat for the prevention of anemia.

The study of Sayuri Sato et al. [13] who is interested in eating habits and iron intake among women of childbearing age, showed that $22.5 \%$ of respondents frequently consumed food sources of iron mainly of vegetable origin (in particular legumes and green leafy vegetables). Inadequate consumption of meat and especially red meat is linked to particular cultural context related to the Mediterranean diet, but the economic level of households. Thus, the achievement of an adequate intake of heme iron could not be realized without improving the purchasing power of the population. Our study showed that among the 124 women anémiques. $45 \%$ had the habit of taking daily tea (iron chelator) immediately after meals. This result is consistent with that of the national 2002 study [5] showed that the simultaneous consumption of tea and food was very prevalent in $54.9 \%$ of anemic women. On the other hand, this study showed the existence of a significant gap between the level of knowledge of anemic women and their practices. Indeed, the majority of women thought that the diet is useful for the prevention and treatment of anemia, in contrast, only 19.4\% regularly followed dietary advice, These results confirm those of other national and international studies [5]-[7] [14] [15]. These data show clearly found the need to intervene for better education of women and girls by the establishment of a nutrition education program associated with other environmental actions. Furthermore, our study revealed that approximately $34 \%$ of anemic women were using herbal remedies to treat their anemia following the advice herbalists. However, plants were prescribed in the same way for all women, regardless of the land and they had flaws. This behavior may cause undesirable effects such as overdose, especially as the dosage is often random (handle, big or small glass spoon). However, the methods of preparation plants (infusion, decoction, maceration,) could cause the destruction or loss of the active substance, or otherwise prevent its extraction and thus could lead to treatment failure. It is therefore essential to know the plant, its chemical composition, its pharmacological properties, indications, side effects, against its indications, its effective dose, duration of therapy and its possible interactions with other plants or treatments to such use is justified, that the treatment is effective and the side effects is minimal. At the end of this work, it should be noted that we found difficult to access at the women surveyed. Given the workload and the large number of patients in consulting services, women spend a long time waiting and therefore they will be psychologiquent tired, she will accept donation difficult to answer our survey.

Similarly we don't find cooperation from herbalists who did not want to answer us because they think that's the secret of their work.

\section{Conclusions}

This study showed that the majority of women surveyed had a moderate or insufficient diet on the anemia knowledge. Our survey showed that $18.5 \%$ of anemic women only frequently consumed food sources of iron, vitamin B12 and folate with a predominance of legumes and green vegetables. There is a significant gap between the level of knowledge of anemic women and their practices in prevention and treatment of anemia. Herbal medicine was prescribed the same for all women, regardless of the field and the flaws they had.

These data clearly found the need to intervene for better education of women and girls by the establishment of a nutrition education program associated with other environmental actions. Although herbal medicine has been and remains a medical method increasingly used, it is necessary that traditional medicine is based on scientific evidence, identifying accurately plants and other natural products that women could use. We must identify helpful remedies and banish those manifestly ineffective.

\section{References}

[1] World Health Organization/United Nations University/Unicef (2001) Iron Deficiency Anemia, Assessment, Prevention 
and Control: A Guide for Programme Managers. WHO, Geneva.

[2] Ben Rayana, M., Kolstern, P., Gharbi, T. and Beghin, I. (2002) Approche causale de l'anémie par carence en fer. La surveillance alimentaire et nutritionnelle en Tunisie. Options Méditerranéennes, 42-49.

[3] Espanel, C., Kafando, E., Hérault, Petit, A., Hérault, O. and Binet, C. (2007) Anémies Ferriprives: Signes d'appel, diagnostic et pris en charge. Transfusion Clinique et Biologique, 14, 21-24. http://dx.doi.org/10.1016/j.tracli.2007.04.005

[4] Ioannou, G.N., Rockey, D.C., Bryson, C.L. and Weiss, N.S. (2002) Iron Deficiency and Gastrointestinal Malignancy: A Population-Based Cohort Study. American Journal of Medicine, 113, 276-280. http://dx.doi.org/10.1016/S0002-9343(02)01214-7

[5] El Ati, J., Lefèvre, P., Béji, C., Ben Rayana, C., Gaigi, S. and Delpeuch, F. (2008) Aetiological Factors and Perception of Anemia in Tunisian Women of Reproductive Age. Public Health Nutrition, 11, 729-736.

[6] Mahmoud Abu-Hasira, A. (2007) Iron Deficiency Anemia among Pregnant Women in Nablus District; Prevalence, Knowledge, Attitude and Practices [Submitted in Partial Fulfillment of the Requirements for the Degree of Master of Public Health Science]. Faculty of Graduate Studies, An-Najah National University, Nablus.

[7] World Health Organization (2002) WHO Strategy for Traditional Medicine 2002-2005. WHO/EDM/TRM/2002.

[8] Konstantin, K. (1995) Les médicaments à base de plantes en Allemagne et dans l'union Européenne ( $1^{\text {ère }}$ partie). Actualités Pharmaceutiques, 329, 64-66.

[9] Kabir, Y., Shahjalal, M., Saleh, F. and Obaid, W. (2010) Dietary Pattern, Nutritional Status, Anemia and Anemia-Related Knowledge in Urban Adolescent College Girls of Bangladesh. Août, 60, 633-637.

[10] Shweta, U., Kumar, A.R., Raghuvanshi, R.S. and Singh, B.B. (2011) Nutritional Status and Knowledge of Hill Women on Anemia: Effect of Various Socio-demographic Factors. Journal of Human Ecology, 33, 29-34.

[11] Heshmat, R., Azemati, B., Keshtkar, A.A., Salehi, F., Abdollahi, Z., Kolahdouz, F., et al. (2009) Comparison of Knowledge, Attitude and Practice of Urban and Rural Households toward Iron Deficiency Anemia in three Provinces of Iran. Iranian Journal of Public Health, 38, 83-90.

[12] WHO, PHI (2004) Health Situation, Statistical \& Policy Reports, Mongolia.

[13] Sayuri Sato, A., Fujimori, E., Cornbluth, S., Szarfarc, A. and Tsunechiro, M. (2010) Food Consumption and Iron Intake of Pregnant and Reproductive Aged Women. The Revista Latino-Americana de Enfermagem, 18, 247-254. http://dx.doi.org/10.1590/S0104-11692010000200016

[14] Judith, L.B. (1997) Food and Nutrition: Attitude, Beliefs and Knowledge in the UK. The American Journal of Clinical Nutrition, 65, 1985S-1995S.

[15] Kalimbira, A.A., Mtimuni, B.M. and Chilima, D.M. (2009) Maternal Knowledge Andpractices Related to Anaemia and Iron Supplementation in Rural Malawi: A Cross-Sectional Study. African Journal of Food, Agriculture, Nutrition and Development Janvier, 9, 550-564. 